\title{
Correspondence
}

\section{ARE DISEASE ENTITIES IN THE MIND? DEAR Sir,}

With an increasing interest in the relevance of epistemology to psychiatry, we would like to comment on the debate between the Newcastle medical and London sociological classifiers of depression/anxiety.

Might not both sides gain by accepting that there are probably no natural taxa? Classes are for purposes. Work in Newcastle seems at least to have shown that we can predict the probable if temporary outcome of ECT. That does not in itself imply that groupings are the best for all treatments, not even that ECT is the 'best' treatment, nor that studies of aetiology will give the same clusters. The value of using factors other than mental state among the criteria for the purpose in hand is testable. Searching for the correct nosology, irrespective of its purpose or our motives, however, seems doomed to produce long statistical debates without rules to determine who has won them. There are not even in fact any 'nonexistent clusters', just many useless and parochial ones, but utility depends on need, desire and purpose. Dimension versus category is also frequently a matter of choice; much depends on assumptions about linearity and about the use of arithmetic on the abscissa of graphs that can produce uni or bipolar curves.

The knower influences the known, especially in psychiatry. Perhaps we would be better advised to state our vision of what could be, as well as struggling to 'objectively classify disease entities'.

F. A. JENNER

J. Damas MORA

P. Ross-Smith

University of Sheffield, Department of Psychiatry, Hallamshire Hospilal, Glossop Road, Sheffield S10 $27 F$

\section{DRUG OR MILIEU?}

DeAr Sir,

De Maio and Levi-Minzi (Journal, July 1979, 135, 73-76) compared three different dosage schedules in treating neurotic depressed patients with Amitriptyline. They find no difference whether the drug is given in the morning, at night, or three times a day. They suggest that, as all patients improved comparably, this was an effect of the drug. This is an unwarranted assumption, particularly as these were all inpatients. They should have had a fourth, drug-free, group: it being my view that if the inpatient milieu is a good treatment situation, this group may well have improved equally.

I am always surprised that organically-minded psychiatrists admit so many neurotic patients when they appear to hold the view that the important therapeutic tool is the drug which, of course, could be given, and at far less cost, to outpatients. (Neurotics are usually avid drug takers and do not need supervision). I submit that we all admit patients not so often because they are a danger to themselves or to others but because the different milieu has considerable healing effects. We are short of studies that evaluate which parts of the milieu are helpful and which parts are not.

Whitecroft Hospital,

IAN G. ThOMson

Sandy Lane,

Newport,

Isle of Wight

\section{HARLOW ON GHILD DEPRIVATION}

DeAr Sir,

Although F. H. Stone in his selection of readings relevant to child psychiatry (Journal, August 1979, 135, 180-1) includes a reference to the WHO monograph in which there is a reassessment of Bowlby's original monograph he fails to do the same with respect to Harlow's work in the same areadeprivation.

Harlow's early work (1959) showed the importance of contact comfort for normal development in the infant monkey. This leads him to say that "the long period of maternal deprivation had evidently left them incapable of forming a lasting affectional tie".

However, the later work of himself and his colleagues has shown that, at least for rhesus monkeys, critical periods do not exist-i.e. that it is possible to habilitate infant monkeys deprived of maternal attachment to the extent that they acquire many normal, species-typical behaviours. These are not lost 